\title{
Basalt Fibers in Modified Whisker Reinforced Cementitious Composites
}

\author{
Mehran Khan ${ }^{1}$, Mingli Cao ${ }^{1 *}$, Hongmei $\mathrm{Ai}^{{ }^{*}}$, Abasal Hussain ${ }^{1}$ \\ ${ }^{1}$ School of Civil Engineering, Dalian University of Technology, Linggong Road, Dalian 116024, Ganjingzi District, Liaoning, PR China \\ *Corresponding author, e-mail: minglic@dlut.edu.cn; ahmei@dlut.edu.cn
}

Received: 19 July 2021, Accepted: 16 December 2021, Published online: 05 January 2022

\begin{abstract}
The calcium carbonate whisker (CW) and basalt fiber are gaining popularity due to its enhanced mechanical properties in composites. Also, the short and long fibers provide bridging role and resistance against cracking from micro- to macro-scale, respectively. The usage of long and short hybrid basalt fiber along with addition of CW in cement-based composites is still a research gap. In this work, experimental behavior of CW basalt hybrid fiber reinforced mortar is considered with various content and length ( $3 \mathrm{~mm}, 6 \mathrm{~mm}, 12$ $\mathrm{mm}$, and $20 \mathrm{~mm}$ ) of hybrid basalt fibers. In addition to this, synergy performance index is determined to quantitatively evaluate the positive interaction of hybrid basalt fiber in cementitious materials. The strengthening effect of whiskers and basalt fibers are also studied using scanning electron microscopy. The CW with various basalt fiber contents having different length of hybrid basalt fiber is used. It was found that the four various length of hybrid basalt fiber together with CW in cement mortar exhibited enhanced compressive, flexural, and split tensile strength than that of pure mortar and single length basalt fiber reinforced cementitious mortar. The results of synergy performance index showed similar trend with the experimental results. The strengthening effect caused by step by step crack arresting mechanism was also observed in cementitious material.
\end{abstract}

Keywords

calcium carbonate whisker, cementitious material, basalt fiber, mechanical properties, synergy performance index

\section{Introduction}

Plain cement-based composites are known to be brittle material that fails without warning. Due to this brittleness, it has relatively low tensile strength and less resistance against cracking [1]. The crack resistance and tensile strength of cement-based composites are improved with the addition of hybrid fibers [2]. Also, the fiber with multi-scale characteristics is extensively used in cement-based composites for strengthening and toughening effect. The cracking at different level can be controlled by using short and long fibers in cementitious composites [1]. The mineral/natural fiber or polymeric fiber are usually helpful in restricting the macro- or meso crack. Therefore, micro-fiber is required to control cracking at micro-level in cement-based composites. The prediction of the properties of the fiber with multi-scale characteristics has been a major barrier, causing widespread applications to be restricted in cementitious composites. To attempt to learn as much as possible about the various mechanical properties of fiber reinforced composites, researchers have proposed using the theoretical fiber factor to predict various mechanical properties. This is mainly because there are few studies that exist about the prediction of the hybrid fiber reinforced composites performance and these studies do not have a hybrid fiber factor included. Based on the governing fiber factor, fiber reinforced composites made with a single type of fiber has been shown to be functional [3-6]. Additionally, particle packing is important because it influences the performance of other materials. Concrete's constitutive behavior is defined by the microscopic particle packing of C-S-H and the associated nano granular mechanics [7-8]. The characteristics of performance in concrete that are mesoscopically visible are caused by the packing of particles at multi-scales in composites. Now, development of sustainable fiber reinforced composites is widely acknowledged to be for maximizing packing density. The calcium carbonate whisker $(\mathrm{CW})$ is needle like inorganic fiber with better resistance to cracking at micro-scale $[1,9]$. Also, basalt fiber is non-decomposable mineral fiber extracted form volcanic rock without 
environmental hazards. The bridging effect of fibers reduces the cracks in cement-based composites [10-14]. The brittleness of cementitious composites are reduced due to the addition of various commercial fibers [15-18]. The basalt fiber has gained consideration of researchers among carbon, polypropylene, glass and steel fibers due to considerable development recently in the field of construction industry $[11,19]$. The less amount of energy is needed during manufacturing process of basalt fiber than that of glass fiber. The low production cost of basalt fiber makes it a suitable replacement material as compared to that of glass and carbon fiber [20-22]. Also, the environmental friendly nature and better mechanical properties of basalt fiber has made it suitable for use in cement-based composites [23, 24]. The propagation of macro- and micro-cracks are restricted due to the bridging effect of long and short fibers, respectively [11]. The best strength properties and impact resistance of cementitious composites can be achieved by using optimal fiber content and fiber type [10, 25]. Therefore, it can be concluded from above discussion that hybridization/ combination of long and short length basalt fibers together with calcium carbonate whisker will strengthen the cementitious composites and play a bridging role at different scales ultimately enhance the mechanical properties.

Nowadays, the researchers are paying attention to the use of inorganic fibers like calcium carbonate whisker and basalt fiber. The basalt fiber is inorganic mineral fiber with good physical and mechanical properties. Also, the whisker is micron size fiber, which resists cracking at microlevel as well as acts as a filler in composites. Single basalt fiber reinforced concrete is investigated by many researchers in the literature $[22,26]$. However, the relevant detail study for the main fundamental properties of hybrid basalt fiber with other kind of micro fiber like whisker is still not available in the field of cementitious composites. Currently, there are two common approaches for mixing of hybrid fibers, i.e. mixing same fibers of various lengths and the second is mixing fibers of various kind/properties. Therefore, both approaches are combined together in this study, the basalt fiber with various kinds and calcium carbonate whisker is used in cement-based composites, which is still unknown. However, the research is still lack about the usage of combination of calcium carbonate whisker with same kind of basalt fiber hybridization having various content and length. In order to further improve the composite reinforcement effect, the whiskers and hybrid fibers of different lengths are mixed together and the synergy performance index is calculated to quantitative analyze the positive effect of hybrid fiber. It is expected that different scale reinforcement systems will be formed in mortar, and the scale effect and performance advantages will be brought into full play to achieve positive synergetic effect.

\section{Experimental work}

The appearance of calcium carbonate whisker (CW) is like white fluffy powder as shown in Fig. 1(a). The chemical composition and micro-morphology of calcium carbonate whiskers obtained in the laboratory are shown in Table 1 and Fig. 1(b), respectively. The aragonite-type calcium carbonate whiskers have needle-like structure with length between 20 and $40 \mu \mathrm{m}$, smooth surface and good dispersion. The various length basalt fibers used in this experiment are shown in Fig. 2 and the properties of basalt fiber provided by manufacturer are shown in Table 2 .

The content of calcium carbonate whisker was $10 \%$, by cement mass. The basalt fibers of different lengths ( $3 \mathrm{~mm}$, $6 \mathrm{~mm}, 12 \mathrm{~mm}$, and $20 \mathrm{~mm})$ and volume content $(0 \%, 0.05 \%$, $0.1 \%$ ) were mixed into cement mortar in a certain proportion. The mortar mix ratio for cement, sand and water was 1,3 and 0.5 , respectively. The sand, fibers, cement and whiskers were dried pre-mixed to make sure that the whiskers

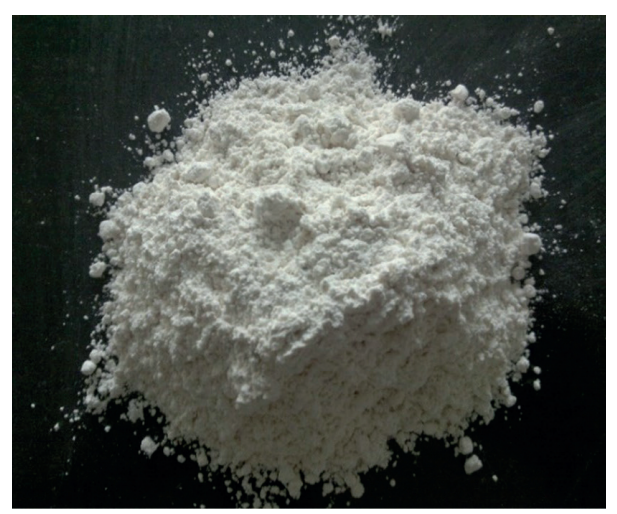

(a)

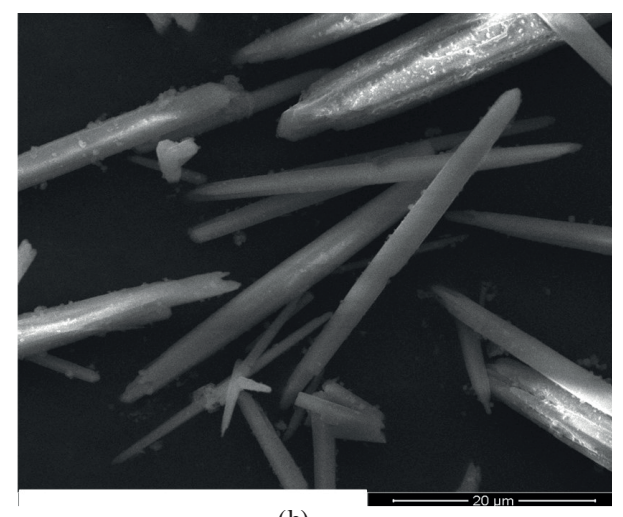

(b)

Fig. 1 Calcium carbonate whisker: (a) Physical appearance; (b) SEM 
and fibers are dispersed uniformly. Then the cement, whiskers, fibers, standard sand and water were stirred consistently by using cement mortar mixer. Lastly, the mortar samples were cast. The molded specimens were kept in the curing room following GB/T50081 [27] standard. Among them, $40 \mathrm{~mm} * 40 \mathrm{~mm} * 160 \mathrm{~mm}$ specimens were cast for compressive and flexural strength tests, $40 \mathrm{~mm} * 40 \mathrm{~mm} *$ $40 \mathrm{~mm}$ specimens were cast for split-tensile strength tests, and $152+3 \mathrm{~mm} * 63.5+3 \mathrm{~mm}$ specimens were cast for impact resistance tests.

Calcium carbonate whiskers were mixed with single and hybrid basalt fibers of various lengths and contents to investigate the composite reinforcing effect. The specific test scheme is shown in Table 3. Among them, CWBFa6L represents the blending of whisker and $6 \mathrm{~mm}$ length fibers; $\mathrm{a}, \mathrm{b}, \mathrm{c}$, and d signify four volumes blending of fibers; CWBF denotes the blending of whisker and hybrid fibers, a1, a2, a3 and a4 represent the four blending modes of $0.05 \%$, total volume blending of fibers; and b1, b2, b3 and b4 represent the four blending modes of $0.1 \%$, total volume blending of fibers.

The compressive and flexural strength was performed according to the GB/T17671 [28] standard. The split-tensile strength test was done considering CECS13:89. Three specimens were cast for each test. The drop weight procedure by ACI544-2R [29] was followed for impact

Table 1 Chemical composition of whiskers

\begin{tabular}{lccccccccccc}
\hline Composition & $\mathrm{CaO}$ & $\mathrm{CO}_{2}$ & $\mathrm{MgO}$ & $\mathrm{SO}_{3}$ & $\mathrm{SiO}_{2}$ & $\mathrm{Al}_{2} \mathrm{O}_{3}$ & $\mathrm{Fe}_{2} \mathrm{O}_{3}$ & $\mathrm{SrO}_{2}$ & $\mathrm{Cr}_{2} \mathrm{O}_{3}$ \\
\hline $\mathrm{Wt}(\%)$ & 54.93 & 42.07 & 2.14 & 0.31 & 0.29 & 0.11 & 0.07 & 0.05 & 0.03 \\
\hline
\end{tabular}

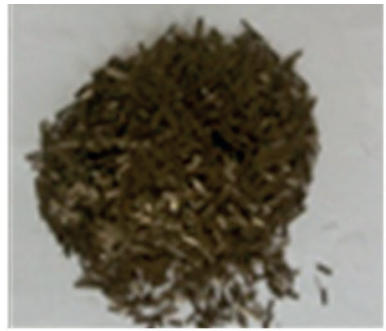

$3 \mathrm{~mm}$

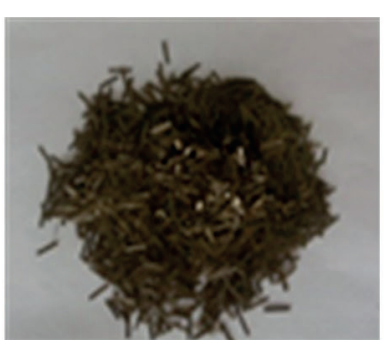

$6 \mathrm{~mm}$

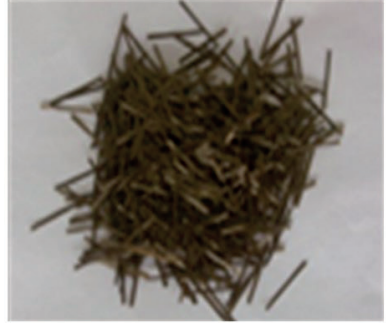

$12 \mathrm{~mm}$

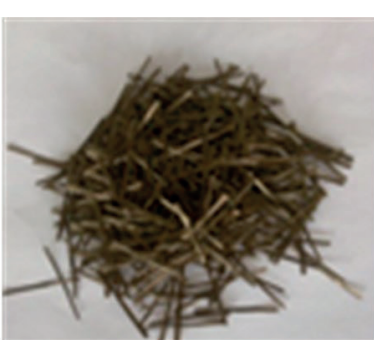

$20 \mathrm{~mm}$

Fig. 2 Various lengths of basalt fiber

Table 2 Properties of basalt fiber

\begin{tabular}{cccccc}
\hline & Diameter $(\mu \mathrm{m})$ & Density $\left(\mathrm{g} / \mathrm{cm}^{3}\right)$ & Breaking strength $(\mathrm{MPa})$ & Elastic modulus $(\mathrm{GPa})$ & Elongation at break $(\%)$ \\
\hline Basalt fiber & 15 & 2.79 & $1323 \sim 1434$ & $7.8 \sim 8.7$ & $2.6 \sim 2.8$ \\
\hline
\end{tabular}

Table 3 Mix proportion of various fibers length and content

\begin{tabular}{|c|c|c|c|c|c|c|}
\hline \multirow[t]{2}{*}{ Mixtures } & \multicolumn{5}{|c|}{ Volume fraction (\%) } & \multirow{2}{*}{$\begin{array}{c}\text { (wt.\%) } \\
\text { CW }\end{array}$} \\
\hline & $3 \mathrm{~mm}$ & $6 \mathrm{~mm}$ & $12 \mathrm{~mm}$ & $20 \mathrm{~mm}$ & Total & \\
\hline Plain & - & - & - & - & - & - \\
\hline CWBFa6L & - & 0.05 & - & - & 0.05 & 10 \\
\hline CWBFb6L & - & 0.1 & - & - & 0.1 & 10 \\
\hline CWHBFa1 & - & 0.025 & 0.025 & - & 0.05 & 10 \\
\hline CWHBFa2 & 0.0167 & 0.0167 & 0.0167 & - & 0.05 & 10 \\
\hline CWHBFa3 & - & 0.0167 & 0.0167 & 0.0167 & 0.05 & 10 \\
\hline CWHBFa4 & 0.0125 & 0.0125 & 0.0125 & 0.0125 & 0.05 & 10 \\
\hline CWHBFb1 & - & 0.05 & 0.05 & - & 0.1 & 10 \\
\hline CWHBFb2 & 0.0333 & 0.0333 & 0.0333 & - & 0.1 & 10 \\
\hline CWHBFb3 & - & 0.0333 & 0.0333 & 0.0333 & 0.1 & 10 \\
\hline CWHBFb4 & 0.025 & 0.025 & 0.025 & 0.025 & 0.1 & 10 \\
\hline
\end{tabular}

Note: CWBF denotes the calcium carbonate whisker basalt fiber reinforced composites. Where a and b represent the total volume content of $0.05 \%$ and $0.1 \%$, respectively. The numbers $1,2,3$, and 4 signifies the hybridization of an equal amount of fibers with different lengths, i.e., two ( 6 mm +12 mm), three $(3 \mathrm{~mm}+6 \mathrm{~mm}+12 \mathrm{~mm})$, and three $(6 \mathrm{~mm}+12 \mathrm{~mm}+20 \mathrm{~mm})$ and four $(3 \mathrm{~mm}+6 \mathrm{~mm}+12 \mathrm{~mm}+20 \mathrm{~mm})$ lengths together, respectively. 
resistance test. The initial cracking impact number $\left(I_{c}\right)$ and final failure impact number $\left(F_{f}\right)$ was observed. Eqs. (1) and (2) were employed to calculate the impact energy after initial cracking and total impact energy, respectively.

$$
\begin{aligned}
& \Delta W=\Delta N \times m g h \\
& W=N_{f} m g h
\end{aligned}
$$

Whereas, $\Delta W$ is impact-energy after initial cracking; $\Delta N$ is taken as the impact number difference between $I_{c}$ and $F_{f} ; N_{f}$ is impact number at $F_{f} ; m$ is steel hammer mass; $h$ is drop height of heavy hammer; $g$ is gravitational acceleration.

When the performance of combination of various fibers exceeds from the performance of single type of fiber due to positive interaction between them then this is commonly known as "fiber synergy". The synergy performance index (SPI) was used in this study to evaluate the various fiber mixing modes quantitatively for the mechanical properties of cementitious composites. The synergy performance index was calculated using Eq. (3).

$$
S P I=\frac{S V c}{S_{1} V c_{1}+S_{2} V c_{2}+S_{3} V c_{3}+\cdots+S_{i} V c_{i}}
$$

Where, $S P I$ is the synergy performance index, $S$ is strength property of whisker basalt fiber reinforced composites, $V c$ is total volume content of different whisker basalt fiber reinforced composites, $S_{i}$ is strength property of single length whisker basalt fibers, $V c_{i}$ is different fibers volume content with various length in hybrid basalt fibers, and $i=1,2,3, \ldots$, and so on. The different basalt fiber lengths reinforcement effect can be quantitively analyze for mechanical properties using synergy performance index. If the performance index is less than 1 then synergy effect is considered as negative and if the value of this index is greater than 1 then the synergy effect is considered as positive.

\section{Mechanical behavior results}

\subsection{Compressive properties}

Fig. 3 demonstrates the compressive strength results of different fiber mixing methods of whisker-fiber reinforced composite. When the total content of single length fiber is $0.05 \%$ and $0.01 \%$, the compressive strength is $6 \%$ and $4 \%$ higher than that of the plain sample, respectively. However, the compressive strength of the whisker-hybrid fiber reinforced composite is also higher, when the fiber content is $0.05 \%$ and $0.01 \%$, than that of single-length fiber composite.

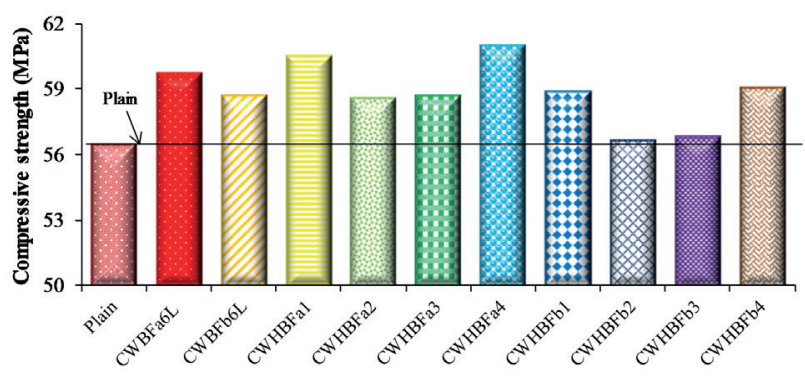

Fig. 3 Compressive strength of all mixes

When the total content of fibers is $0.05 \%$, the compressive strength of CWHBFa4 is the highest, which is slightly more than that of whisker-single fiber length specimens. The CWHBFb4 compressive strength is improved by $8 \%$, as to that of blank samples. When the total fiber content is $0.1 \%$, the reinforcing effect of CWHBFb4 is the best, compared with plain and single length fiber specimens. Therefore, it can be seen that whisker and four kinds of fibers with different lengths show the best composite reinforcement effect, and is superior as compared to the whisker with single length fibers. When the whisker content is $10 \%$ and with $0.05 \%$ basalt fiber content, the compressive strength of mortar is the maximum with whisker and four different length fibers. The reason behind the maximum strength is that the addition of multi-scale various basalt fiber reinforcement play their role at multi-level and restrict the crack propagation by providing the confinement effect ultimately increase the mechanical performance. Also, the inclusion of whisker enhanced the strength of the matrix by improve the compactness due its filler effect.

The mode of failure for mortar sample containing basalt fiber was different under compressive load as to that of plain samples. The plain mortar sample demonstrates the brittle failure and after the cracking pieces were chipped off. However, the less brittle failure was observed for whisker-hybrid fiber reinforced composite with finer crack size and good integrity, as compared to that of plain composite. The increase fiber content improved the failure mode of whisker basalt fiber cement mortar because addition of basalt fibers results in restricting the crack convergence and propagation ultimately consuming more energy.

The synergy performance index quantitively estimates the effect of hybridization of different fiber content and length in term of strength properties. Fig. 4 shows the calculated synergy performance index of all mixes with various fiber lengths and content. Among all mixes, the highest enhancement effect was observed with four kind of different length fibers (CWHBFa4). The CWHBFa2, CWHBFa3, CWHBFb2 and CWHBF3 demonstrate the 


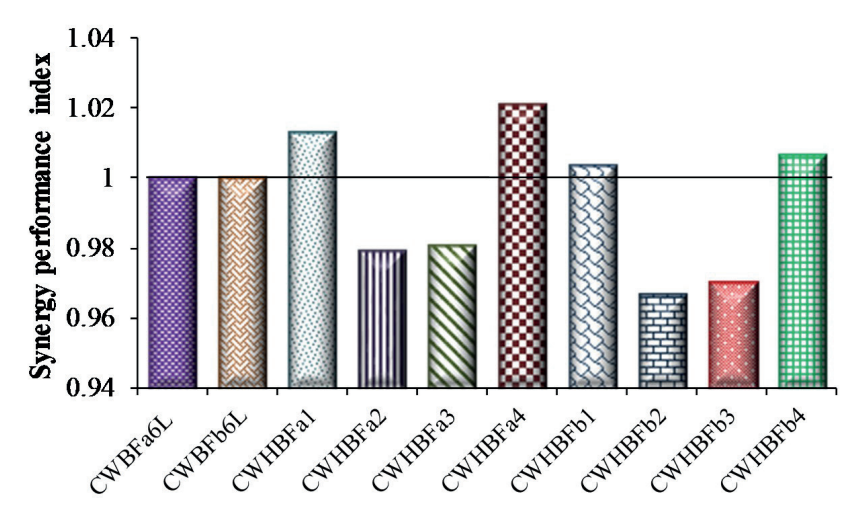

Fig. 4 Compressive strength synergy performance index

negative hybrid fiber effect with performance index less than 1. It is worth mentioning that the trend of compressive strength and synergy performance index is similar in case of hybridization of four kind of different length fibers. Also, the negative synergy performance is found for two and three kinds of fibers blends. Therefore, the quantitative performance of compressive strength for various kind of fiber blended together can be predicted with the help of synergy performance index for hybridization of four kind of different length fibers.

\subsection{Flexural properties}

Fig. 5 shows the result of various fiber mixing methods on flexural strength of whisker-fiber reinforced composite. It can be seen from the Fig. that with increasing the fiber content, the flexural strength increases. When the total fiber content of single length fiber is $0.1 \%$, the flexural strength of the specimens is increased by $14 \%$, compared with the blank specimens. When the total fiber content is $0.05 \%$, the flexural strength of whisker-fiber mortar with various fiber is greater as to that of blank samples. Among them, the CWHBFa4 composite mixing type has the most remarkable effect. The flexural strength of whisker-fiber mortar is $17 \%$ higher than that of blank samples and the increase is larger than single fiber length sample. When total fiber content is $0.1 \%$, the flexural strength of whisker-hybrid fiber reinforced composite is increased by $16 \%$, which is higher than that of the blank sample and single-fiber length sample. When the type of whisker-fiber composite is $\mathrm{CWHBFb} 4$, the flexural strength of whisker-fiber mortar is the highest. Therefore, the strengthening effect of whisker and four different length fibers is improved than that of whisker with single length fibers having two total volume contents of $0.05 \%$ and $0.1 \%$. When the fiber content is $0.05 \%$, the flexural strength of mortar with whisker and four various length fibers increases to the maximum, and the composite reinforcement effect is the best. The bridging effect provided by multi-scale basalt fibers restrict the development of cracks and ultimately increase the flexural performance of composite.

The brittle cracking sound was observed when the plain sample was broken into two sections under flexural loading. However, the ductile failure was shown by the whisker-hybrid fiber reinforced composite. The plain mortar sample was fragmented into two pieces while the whisker basalt fiber sample was in contact and showed fiber bridging. The matrix integrity was improved by uniformly distributed fibers which result in fiber bridging finally reduce the stress concentration in composite. Also, the toughness of mortar sample was improved consuming more destructive energy caused by pull out of fibers.

The positive effect of hybrid fiber mixing for flexural strength with various whisker-fiber reinforced composite is shown in Fig. 6. The best synergy performance index is shown by CWHBFa4 having different kind of fiber length and content. The synergy performance index of whisker basalt fiber reinforced mortar with total volume fraction of $0.05 \%$ is more than that of $0.01 \%$ total volume content. Furthermore, increase in total fiber volume content result in decrease hybrid reinforcement effect for various kinds of basalt fibers. The CWHBFa4 showed the best reinforcement effect with four various lengths of fibers having total content of $0.05 \%$. Moreover, the trend shown by synergy

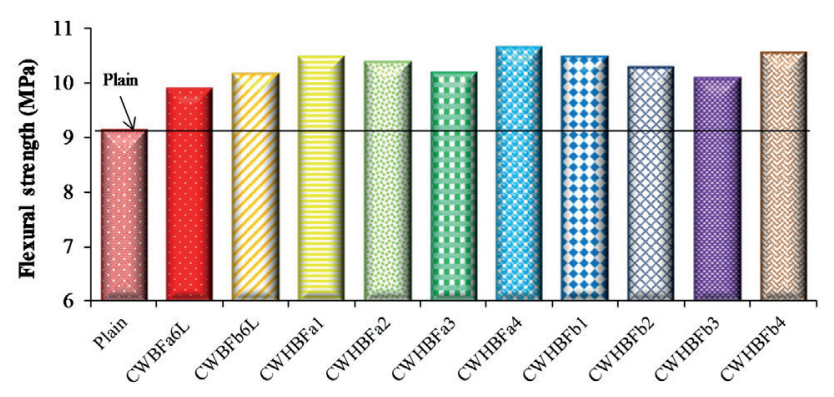

Fig. 5 Flexural strength of all mixes

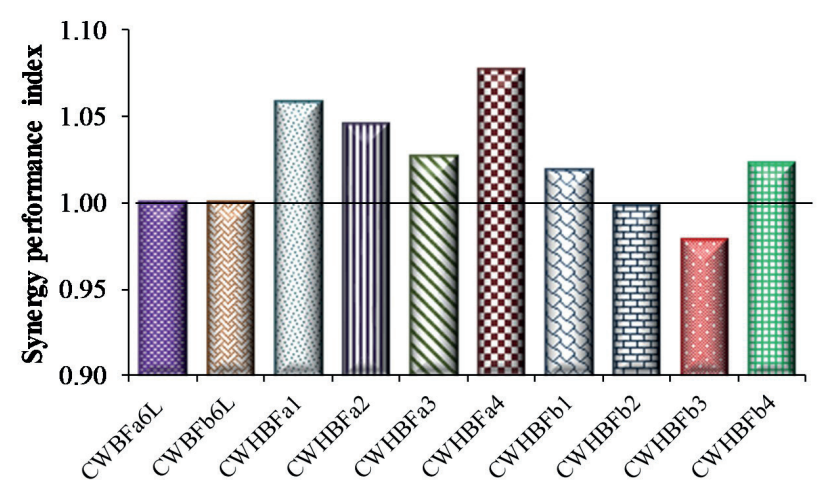

Fig. 6 Flexural strength synergy performance index 
performance index is same as the trend demonstrated by flexural strength. This indicates that the hybridization effect can be predicated with the help of synergy performance index for various fiber lengths and contents.

\subsection{Split-tensile properties}

The comparison between the split-tensile strength of plain and whisker-hybrid fiber reinforced composite are illustrated in Fig. 7. It may be noted that when the total fiber content of single fiber length is $0.1 \%$, the split-tensile strength of whisker-hybrid fiber reinforced composite is $22 \%$ higher than that of blank sample. The split-tensile strength of samples with whisker-hybrid fiber reinforced composite is enhanced by different extent. When the total fibers content is $0.05 \%$, the reinforcing effect of whisker-fiber blending type CWHBFal and CWHBFa4 is better than that of whisker-fiber blending type CWBF6aL, and the reinforcing effect of $\mathrm{CWHBFa} 4$ is the most remarkable. The strengthening effect of CWHBFa4 is $24 \%$, greater than that of blank sample. When the fiber content is $0.1 \%$, the trend is similar to that of $0.5 \%$ fiber content. The split-tensile strength of CWHBFa4 and CWHBFb4 is obviously higher than that of CWBF6a (single fiber length). The split-tensile strength of $\mathrm{CWHBFb} 4$ with the best strengthening effect is $25 \%$ and $3 \%$, more than that of blank and non-whisker blended $\mathrm{CWBFb} 6 \mathrm{~L}$, respectively. Therefore, when the whisker content is $10 \%$ and the fiber content is $0.1 \%$, the split-tensile strength of composite material mixed with four various fiber lengths is the best. The tensile strength of composites is increased due to the bridging effect offered by multi-scale basalt fibers that help in controlling the growth of cracks at different scale.

The plain sample was split into the two parts at the failure load and showed brittle failure. The fracture at the cross section of plain sample was uniform and flat. On the other hand, the crack bridging and good integrity was found in whisker basalt fiber reinforced mortar. Also, more cracks were produced along with the force direction

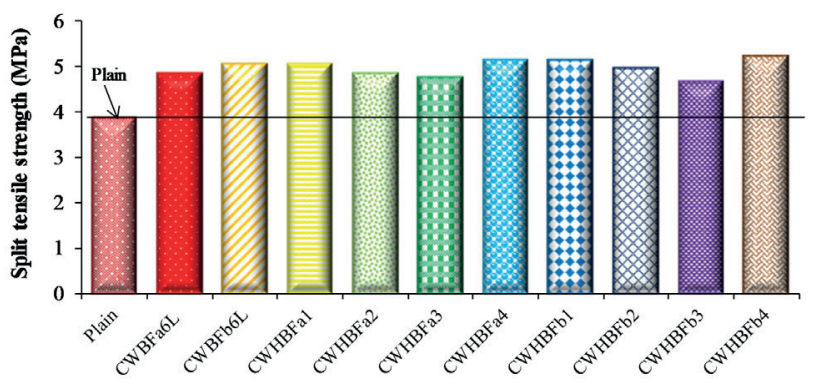

Fig. 7 Split-tensile strength of all mixes by changing the path of primary crack to secondary cracks ultimately delaying the failure process of sample. The growth of these secondary cracks consumed additional destructive energy due to slow crack prorogation eventually improved the tensile strength.

The synergy performance index of split tensile strength with various whisker basalt fiber mortars are presented in Fig. 8. The positive hybrid fiber effect with four various kind of basalt fiber blend in each group is maximum than that of other hybrid fibers. The synergy performance index of whisker basalt reinforced mortar with $0.05 \%$ is higher than that of $0.1 \%$ total volume content. The trend shown by synergy performance index is also similar with the trend of split-tensile strength. The CWHBFa4 with four various kind of fiber having $0.05 \%$ total volume content has the best enhancement effect as compared to all other whisker basalt fiber reinforced mortar.

\subsection{Impact resistance properties}

Fig. 9 shows the result of whisker-hybrid fiber reinforced composite on initial cracking and final failure impact number. The mortar impact resistance is greatly improved after whisker and fiber are mixed. In comparison with single fiber length sample, the impact number of initial cracking with various length fibers is increased. When the content of fibers is $0.1 \%$, the initial cracking impact number and failure shocks reach the maximum. The impact times at final failure of whisker-hybrid fiber reinforced composite are greatly increased under four different fiber mixing modes, and the reinforcement effect of whiskers and hybrid fibers is best than that other fiber length sample.

Figs. 10(a) and 10(b) displays the impact energy absorbed by whisker and fiber reinforced cement mortar samples. Under each fiber content, the impact energy absorbed by whisker and fiber composite reinforced cement mortar specimens is increased by different extents. However, for

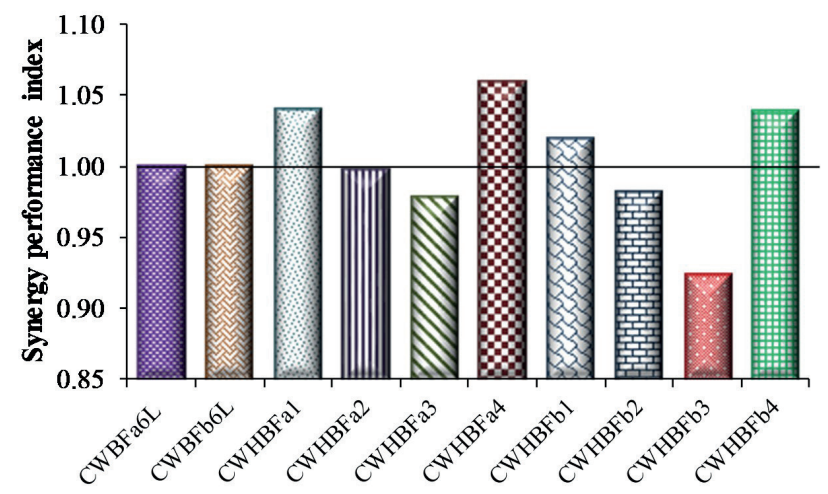

Fig. 8 Split tensile strength synergy performance index 
the post-crack impact energy, the change is small and has not been improved by whisker incorporation, which indicates that the composite whiskers and fibers do not enhance the loading capacity of mortar after initial cracking as compared to that of total impact energy. From the impact energy point of view, the total impact energy absorbed by the composite whisker and fibers is much higher than that of the blank sample, and CWHBFb4 demonstrate the highest. It shows that the composite material with whisker and fibers of different lengths can reduce the stress concentration in the matrix, consume and absorb more energy, and thus improve the impact resistance of the matrix more effectively. Therefore, when the whisker content is $10 \%$ and fiber content is $0.1 \%$, the combination of whisker with four various fiber length results in best properties.

The brittle failure was noted in plain mortar under impact loading having a crack and the sample was split into two parts along the diameter direction as shown in Fig. 11. The multi-cracks and certain degree of toughness was observed in whisker basalt fiber mortar due to the formation

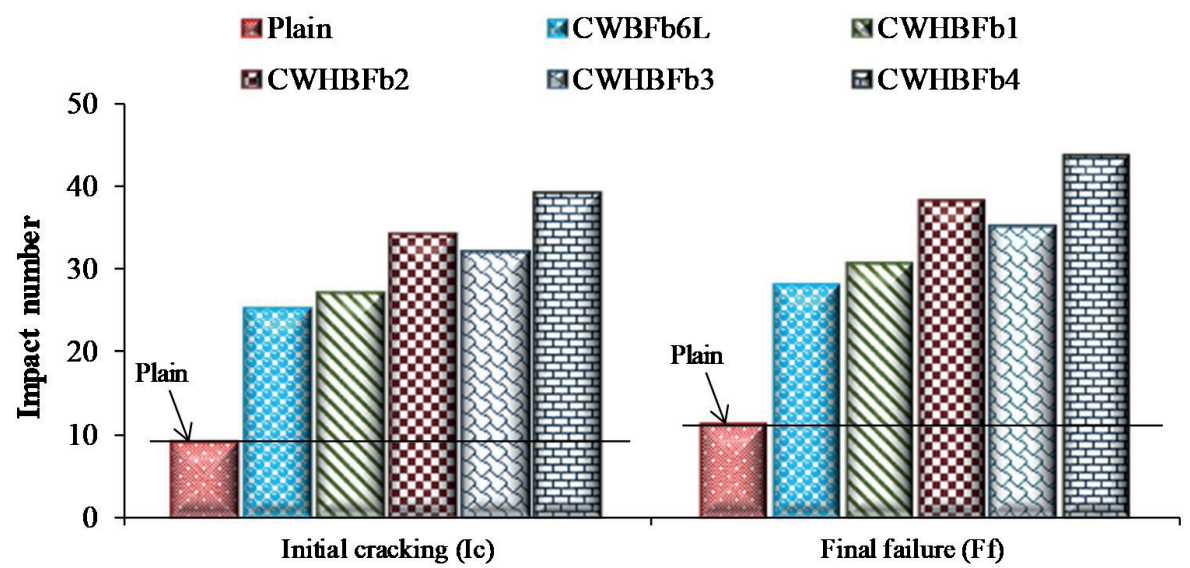

Fig. 9 Impact number of various mixes

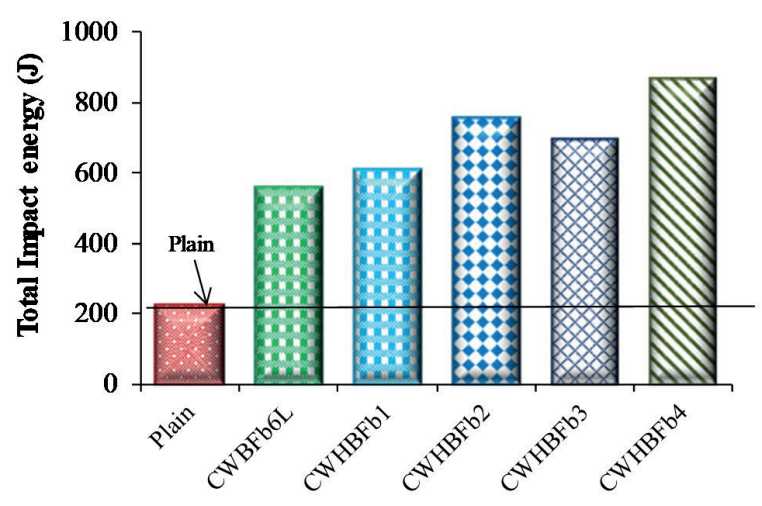

(b)

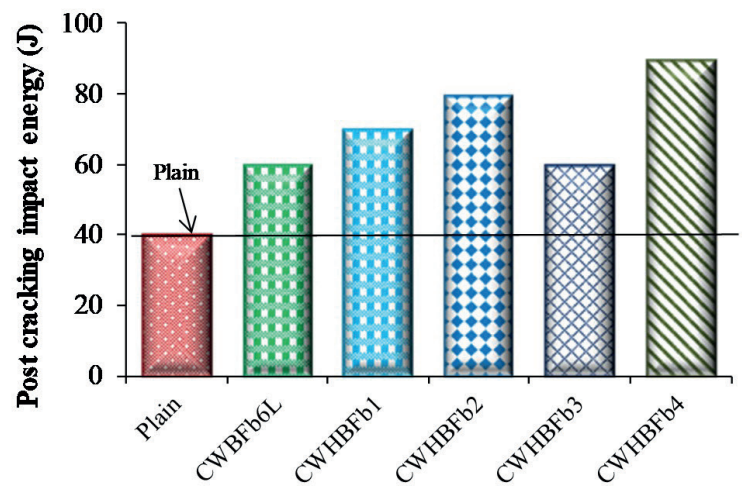

Fig. 10 Impact energy of various mixes: (a) Total; (b) Post cracking

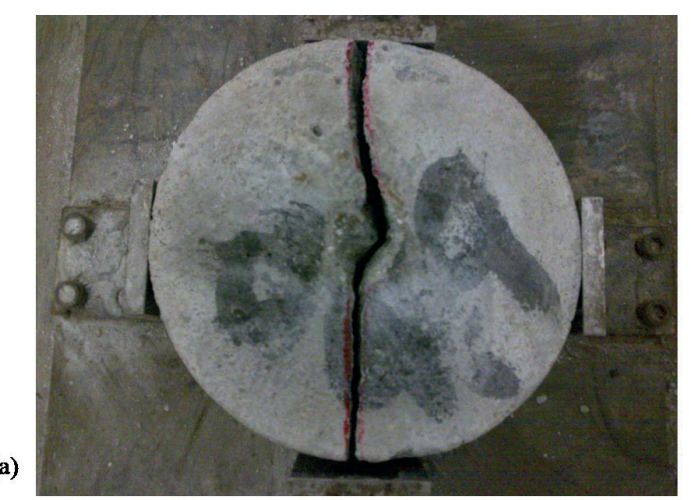

(b)

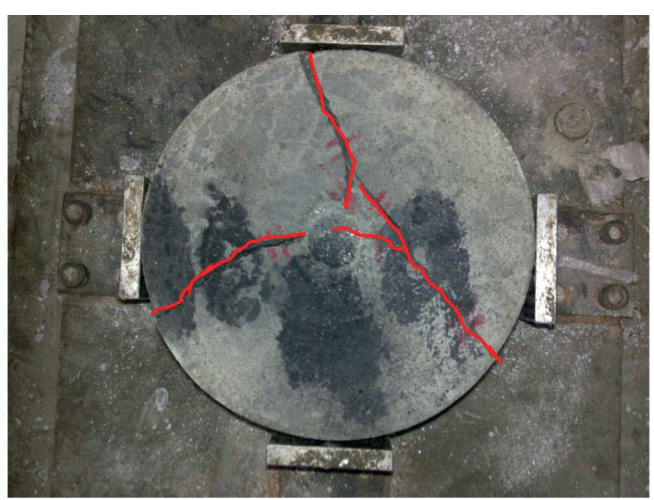

Fig. 11 Specimens after impact test: (a) Plain composite; (b) Whisker-hybrid basalt fiber reinforced composite 
of small crack under applied impact load. Moreover, basalt fibers addition give rise to the number of micro-cracks around the main crack due to their bridging effect. This may be due to the bridging effect of fibers resulted in redistribution of stress in matrix eventually lead to energy dissipation mechanism. However, more energy was consumed by generation of more micro-cracks, which help in reducing the stress concentration of main crack, and delay the failure process ultimately improved strength.

Fig. 12 demonstrates the synergy performance index calculated for impact number and impact energy. The synergy performance index is greater than 1 for both impact number and impact energy, which shows the positive hybrid mixing effect. The best positive hybrid mixing effect is shown by four different lengths of fiber blended together. It is worth noting that impact number and energy synergy performance index show similar trend as compared to that impact number and impact energy. Thus, the synergy performance index can be used to estimate the hybridization effect of fibers quantitatively for various kind of fibers blended together.

\section{Microstructural analysis}

The mechanical properties of mortar can be effectively enhanced by mixing whisker and fiber in a reasonable amount. The different length hybrid fiber reinforced cement mortar with whisker shows better strengthening effect than that single fiber length sample which achieved the purpose of composite reinforcement. This is mainly attributed to the fact that whiskers and basalt fibers have different scales and properties. They can reinforce and toughen the matrix at different stages of loading on mortar, so that whiskers and fibers can give full play to the advantages of scale and performance, and form complementary advantages, thus producing synergistic effect.

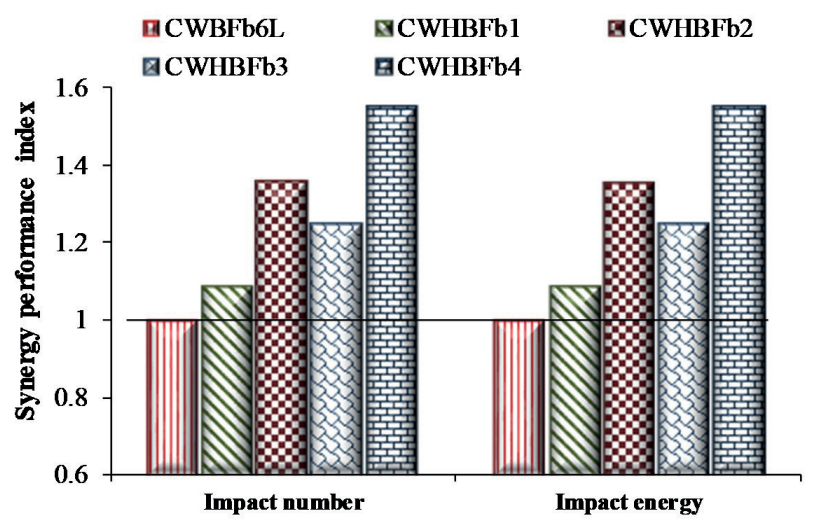

Fig. 12 Synergy performance index of impact number and impact energy
For the scale and properties of whiskers, calcium carbonate whiskers belong to the sub-micron scale category, and have higher modulus of elasticity and lower elongation at break. For basalt fibers, the size is relatively large, the diameter is in the micron scale category, and has more prominent elongation at break. This determines that whiskers and fibers will occur at different structural levels and loading stages and play the role of strengthening and toughening. In the initial stage, when the matrix is subjected to external loads, the calcium carbonate whisker plays a major role in strengthening the matrix at the micro level depending on its ultra-fine size and excellent mechanical properties. Due to the relatively low internal stress and small scale of primary microcracks, whiskers can effectively prevent the initiation and propagation of microcracks by bridging, mainly by reducing the number and scale of crack sources.

The whiskers result in small "energy dissipation mechanism" and can reduce the stress concentration range at the crack tip by pulling out a large number of whiskers to produce energy dissipation. This process slows down the generation and extension of microcracks at whisker scale, delays the appearance of initial crack points and improves the initial crack strength of matrix. As the load continues to increase, microcracks further expand but before reaching the maximum load, whiskers and fibers play a joint role in enhancing the crack resistance in their respective scales. When microcracks gradually converge into larger-scale microcracks or even local cracks, basalt fibers start bridging role against cracks at a more macroscopic structural level. The expansion is hindered, which further limits the extension and development of large-scale cracks. When the maximum load matrix begins to destabilize, some fibers are pulled out from the cracked matrix, depending on its good elongation and large aspect ratio, which consumes a lot of energy. This overcome the friction shear force between fibers and matrix, effectively slows down the failure speed, so that the load does not suddenly drop, but produces a very short time, so that the matrix presents toughness. It can be seen that the effect of composite reinforcement is mainly attributed to the whiskers and various size and properties of fibers, which play a strengthening role at the particular stages and form complementary performance advantages in the process of matrix structure formation and stress of composites.

In addition, the strengthening effect of whisker with four different fiber lengths is more remarkable as to that of whisker with single fiber length. This fully shows the 
corresponding matching relationship between whisker and hybrid fibers on scale and the structure level of mortar, which is more helpful to the enhancement and toughening of matrix during the process of loading. Whiskers and various basalt fibers of corresponding sizes are strengthened to limit the generation and number of crack sources, reduce crack sizes at all levels and prevent the development of macro-cracks, and play a synergistic and complementary role with each other, resulting in the effect of step-by-step crack resistance and strengthening. Fig. 13 shows the microstructure of whisker-fiber cement mortar under scanning electron microscopy. It can be seen that cement hydration is more sufficient, cement paste is more compact, calcium carbonate whiskers and basalt fibers are distributed randomly in the matrix. Among them, the distribution of whiskers and fibers in the matrix and the relationship between size and scale can be clearly seen from the Fig. 13(a) and Fig. 13(b). They are well integrated with the cement matrix and are more closely related to the cement paste bonding part. In addition, some basalt fibers are poorly dispersed in the mortar matrix, and there exists clustering phenomenon as shown in Fig. 13(c).

(a)
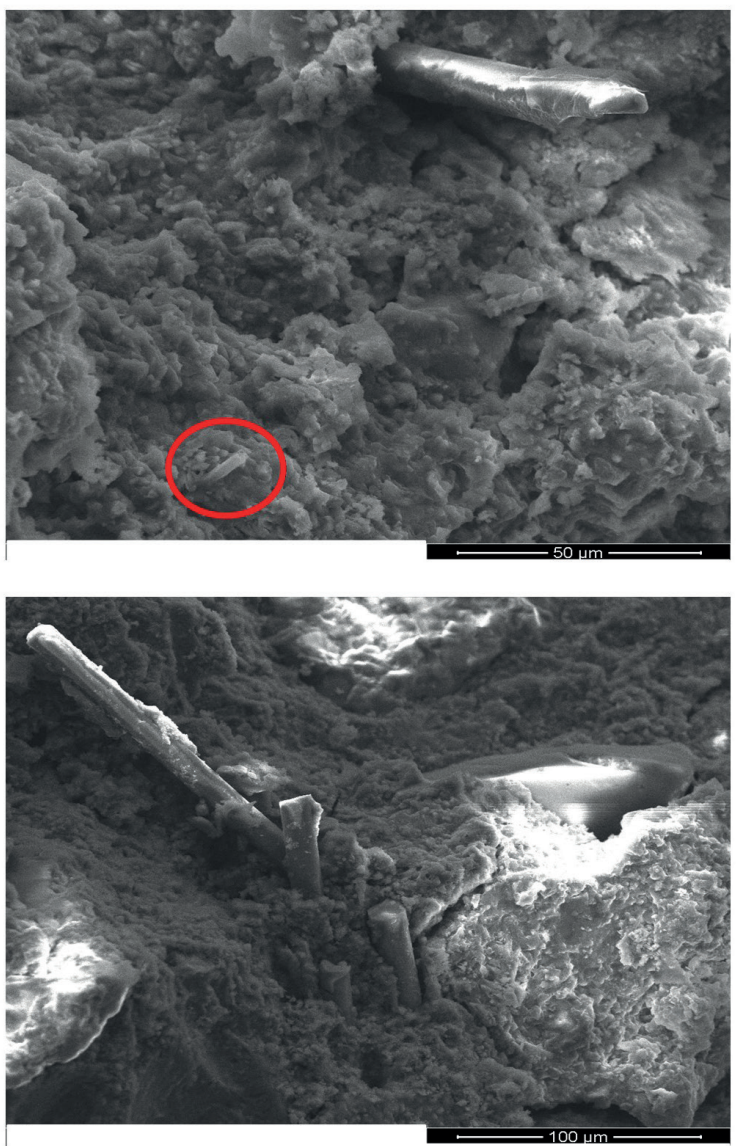

(b)

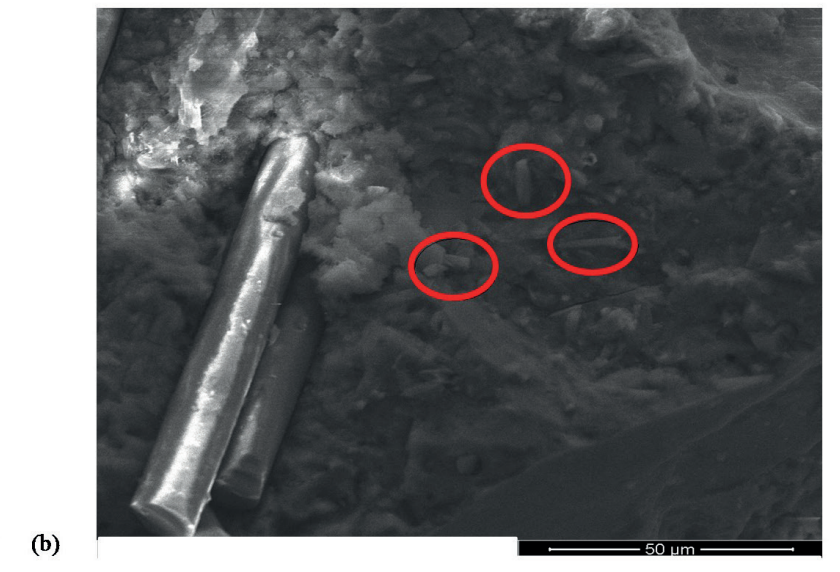

This will not only lead to the increase of internal defects, but also cause the unbalance of fiber spacing, thus weakening the reinforcing and toughening effect of the fibers to a certain extent. However, it can also be found from Fig. 13(d) that the surface of basalt fibers pulled out from the matrix is relatively smooth and there is no residual cement hydrate which indicates low bond strength. The addition of higher fiber content results in heterogeneity of the mix that may cause low bond strength between fibers and matrix ultimately results in low strength properties. The indentation left behind by the peripheral fibers can further indicate that bond strength between basalt fiber and matrix is not optimal. This will have adverse effects on the properties of cement mortar, so the interface performance still needs to be further study in future.

\section{Conclusions}

In this study, the effect of various kind of basalt fiber on the mechanical properties of calcium carbonate whisker cementitious materials were studied experimentally and compared with that of plain and single length basalt fiber reinforced composite. Following conclusions are made:

(d)

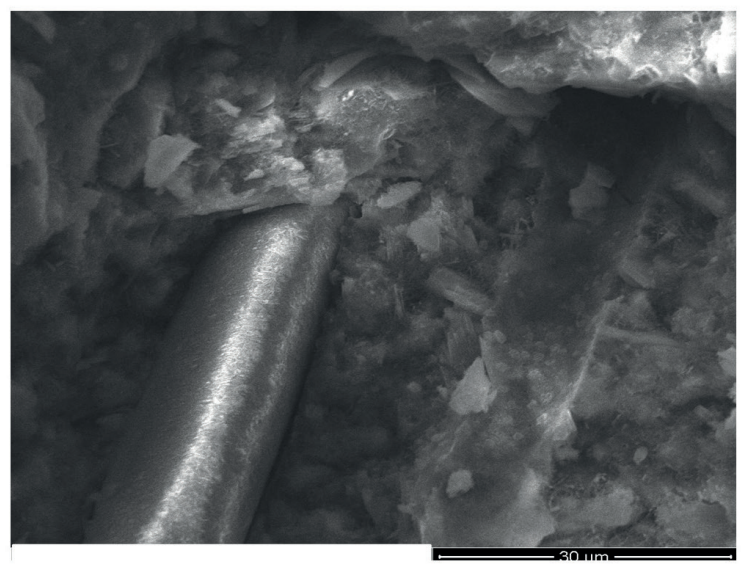

Fig. 13 SEM images of whisker-fiber cement mortar 
- The mechanical properties of composite reinforced with $10 \%$ whisker and four various lengths of hybrid basalt fibers having different contents are enhanced over that of pure mortar and single length basalt fiber reinforced mortar. The compressive strength of mortar is improved up to $7 \%$, than that of plain mortar. The flexural strength of whisker hybrid fiber reinforced composite is enhanced up to $17 \%$, than that of plain composite. Compared with the plain mortar, the split-tensile strength of sample is increased up to $35 \%$.

- The composite blended with whisker and hybrid fibers enhanced the impact resistance greatly under different fiber mixing modes and the strengthening effect is improved than that of whisker and single fiber length sample. However, there is no significant change observed in the ability of the specimen to absorb impact energy after initial cracking.

- The results obtained from synergy performance index showed the same trend in accordance with the trend of experimental results for hybridization of four kinds of different length fibers.

\section{References}

[1] Cao, M., Xie, C., Li, L., Khan, M. "Effect of different PVA and steel fiber length and content on mechanical properties of $\mathrm{CaCO} 3$ whisker reinforced cementitious composites", Materiales de Construcción, 69(336), Article ID e200, 2019.

https://doi.org/10.3989/mc.2019.12918

[2] Kizilkanat, A. B. "Experimental Evaluation of Mechanical Properties and Fracture Behavior of Carbon Fiber Reinforced High Strength Concrete", Periodica Polytechnica Civil Engineering, 60(2), pp. 289-296, 2016.

https://doi.org/10.3311/PPci.8509

[3] Chu, S. H., Li, L. G., Kwan, A. K. H. "Fibre factors governing the fresh and hardened properties of steel FRC", Construction and Building Materials, 186(20), pp. 1228-1238, 2018.

https://doi.org/10.1016/j.conbuildmat.2018.08.047

[4] Chu, S. H., Ye, H., Huang, L., Li, L. G. "Carbon fiber reinforced geopolymer (FRG) mix design based on liquid film thickness", Construction and Building Materials, 269, Article number: 121278, 2021.

https://doi.org/10.1016/j.conbuildmat.2020.121278

[5] Chu, S. H., Li, L. G. Kwan, A. K. H. "Development of extrudable high strength fiber reinforced concrete incorporating nano calcium carbonate", Additive Manufacturing, 37, Article number: 101617, 2021.

https://doi.org/10.1016/j.addma.2020.101617

[6] Chu, S. H., Kwan, A. K. H. "Mixture design of self-levelling ultrahigh performance FRC", Construction and Building Materials, 228, Article number: 116761, 2019.

https://doi.org/10.1016/j.conbuildmat.2019.116761
- Whiskers and basalt fibers can produce composite reinforcing effect mainly due to the different scale and performance characteristics. The matrix reinforced with whisker and basalt fibers is strengthen and toughen at different structural levels giving full play to scale effect and performance advantages, and forming complementary advantages. Thus, the effect of systematic crack resistance and strengthening is produced.

\section{Acknowledgements}

The authors would like to acknowledge the support of this work by the Natural Science Foundation of China under Grant No. 51678111 and No. 51478082. The financial support from China Scholarship Council (CSC) for PhD studies of Engr. Dr. Mehran Khan at Dalian University of Technology, China is gratefully acknowledged. The authors are also thankful to Dr. Cao Mingli research group for their help during the lab work. The careful review and constructive suggestions by the anonymous reviewers are gratefully acknowledged.

[7] Chu, S. H. "Development of Infilled Cementitious Composites (ICC)", Composite Structures, 267, Article number: 113885, 2021. https://doi.org/10.1016/j.compstruct.2021.113885

[8] Chu, S. H., Chen, J. J., Li, L. G., Ng, P. L., Kwan, A. K. H. "Roles of packing density and slurry film thickness in synergistic effects of metakaolin and silica fume", Powder Technology, 387, pp. 575-583, 2021.

https://doi.org/10.1016/j.powtec.2021.04.029

[9] Cao, M., Khan, M., Ahmed, S. "Effectiveness of Calcium Carbonate Whisker in Cementitious Composites", Periodica Polytechnica Civil Engineering, 64(1), pp. 265-275, 2020. https://doi.org/10.3311/PPci.14288

[10] Ralegaonkar, R., Gavali, H., Aswath, P., Abolmaali, S. "Application of chopped basalt fibers in reinforced mortar: A review", Construction and Building Materials, 164, pp. 589-602, 2018. https://doi.org/10.1016/j.conbuildmat.2017.12.245

[11] Sadrmomtazi, A., Tahmouresi, B., Saradar, A. "Effects of silica fume on mechanical strength and microstructure of basalt fiber reinforced cementitious composites (BFRCC)", Construction and Building Materials, 162, pp. 321-333, 2018. https://doi.org/10.1016/j.conbuildmat.2017.11.159

[12] Khan, M., Ali, M. "Effect of super plasticizer on the properties of medium strength concrete prepared with coconut fiber", Construction and Building Materials, 182, pp. 703-715, 2018. https://doi.org/10.1016/j.conbuildmat.2018.06.150

[13] Khan, M., Ali, M. "Improvement in concrete behavior with fly ash, silica-fume and coconut fibres", Construction and Building Materials, 203, pp. 174-187, 2019. https://doi.org/10.1016/j.conbuildmat.2019.01.103 
[14] Khan, M., Rehman, A., Ali, M. "Efficiency of silica-fume content in plain and natural fiber reinforced concrete for concrete road", Construction and Building Materials, 244, Article number: 118382, 2020.

https://doi.org/10.1016/j.conbuildmat.2020.118382

[15] Chiranjeevi Reddy, K., Subramaniam, K. V. "Experimental investigation of crack propagation and post-cracking behaviour in macrosynthetic fibre reinforced concrete", Magazine of Concrete Research, 69(9), pp. 467-478, 2017.

https://doi.org/10.1680/jmacr.16.00396

[16] Lee, J.-H., Yoo, D.-Y., Yoon, Y.-S. "Mechanical behaviour of concrete with amorphous metallic and steel fibres", Magazine of Concrete Research, 68(24), pp. 1253-1264, 2016. https://doi.org/10.1680/jmacr.15.00493

[17] Tran, T. K., Kim, D. J. "Investigating direct tensile behavior of high performance fiber reinforced cementitious composites at high strain rates", Cement and Concrete Research, 50, pp. 62-73, 2013. https://doi.org/10.1016/j.cemconres.2013.03.018

[18] Shiri, S., Abbasi, M. H., Monshi, A., Karimzadeh, F. "A study on mechanical and physical properties of monocalcium aluminate cement reinforced with nano-SiO2 particles", Composites Part B: Engineering, 56, pp. 30-33, 2014.

https://doi.org/10.1016/j.compositesb.2013.08.057

[19] Wang, X., Wang, Z., Wu, Z., Cheng, F. "Shear behavior of basalt fiber reinforced polymer (FRP) and hybrid FRP rods as shear resistance members", Construction and Building Materials, 73, pp. 781789, 2014.

https://doi.org/10.1016/j.conbuildmat.2014.09.104

[20] Algin, Z., Ozen, M. "The properties of chopped basalt fibre reinforced self-compacting concrete", Construction and Building Materials, 186, pp. 678-685, 2018.

https://doi.org/10.1016/j.conbuildmat.2018.07.089
[21] Lopresto, V., Leone, C., De Iorio, I. "Mechanical characterisation of basalt fibre reinforced plastic", Composites Part B: Engineering, 42(4), pp. 717-723, 2011.

https://doi.org/10.1016/j.compositesb.2011.01.030

[22] Kabay, N. "Abrasion resistance and fracture energy of concretes with basalt fiber", Construction and Building Materials, 50, pp. 95-101, 2014. https://doi.org/10.1016/j.conbuildmat.2013.09.040

[23] Qin, J., Qian, J., Li, Z., You, C., Dai, X., Yue, Y., Fan, Y. "Mechanical properties of basalt fiber reinforced magnesium phosphate cement composites", Construction and Building Materials, 188, pp. 946955, 2018.

https://doi.org/10.1016/j.conbuildmat.2018.08.044

[24] Branston, J., Das, S., Kenno, S. Y., Taylor, C. "Mechanical behaviour of basalt fibre reinforced concrete", Construction and Building Materials, 124, pp. 878-886, 2016.

https://doi.org/10.1016/j.conbuildmat.2016.08.009

[25] Dawood, E. T., Ramli, M. "The effect of using high strength flowable system as repair material", Composites Part B: Engineering, 57, pp. 91-95, 2014.

https://doi.org/10.1016/j.compositesb.2013.09.048

[26] Di Ludovico, M., Prota, A., Manfredi, G. "Structural upgrade using basalt fibers for concrete confinement", Journal of Composites for Construction, 14(5), pp. 541-552, 2010. https://doi.org/10.1061/(ASCE)CC.1943-5614.0000114

[27] CNIS "GB/T50081 Standard for Test Method of Mechanical Properties on Ordinary Concrete", China National Institute of Standardization, Beijing, China, 2002.

[28] CNIS "GB/T17671 Method of testing cement-determination of strength", China National Institute of Standardization, Beijing, China, 1999.

[29] ACI Committee 544 "ACI544-2R, Measurement of properties of fiber reinforced concrete", American Concrete Institute, Farmington Hills, MI, USA, 1999. 